are particularly influenced by the power of advertising, hence cigarette manufacturers spend vast sums of money suggesting their products are trendy, sexy and alluring. The tobacco companies are unscrupulous, and as yet haven't been brought to task for the enormous impact their product has had on the health of the nation. The number of smokers choosing to quit is rising but there is an alarming number of young people, particularly females, starting smoking.

'Putting tobacco in plain packaging would be a significant step in allowing people to take a more balanced view as to whether to start smoking or not. It is unlikely to make any difference to existing smokers. Seventy percent of smokers would like to quit; their opportunity to do so may lie with a dental professional. Existing smokers are in a different position to that of non-smokers contemplating smoking. Most smokers are addicted even if they believe they are not. Tobacco addiction is powerful and very hard to overcome. Dental professionals are in a unique position to provide the support necessary for smokers whose decision to continue smoking is influenced by their addiction rather than advertising.'

\section{THE SMOKER}

John, a 35-year-old male smoker from South London (who also holds a PgDip in public health and health promotion):

'Personally I don't understand where the blank packets initiative has come from. Recent initiatives including banning cigarettes being called "lights" or "mild" and tobacco products being kept out of sight in big supermarkets seem to be to try and stop people starting smoking in the first place. These are quite obvious in intent and part of a long term plan to stop new smokers but don't address the core $25 \%$ of the UK population who don't want to stop. I also can't see how blank packets are linked to any kind of behaviour change model as all health promotion activities should be. Blank packets may have the opposite effect - similar to the ban of smoking in pubs, blank packets may become a talking point, "which brand have you got?" The shock value of changing the photographs of people with smoking-related illnesses on packets wears off quickly. More graphic photos on packets - such as in Thailand - will probably be more effective, although my non-smoking acquaintances seem to be more disturbed by these photos than I am. Blank packets certainly won't stop me smoking - only willpower and a desire to stop which I don't have right now.'

Since the above views were collated, Public health minister, Jane Elliston, announced that paediatrician Sir Cyril Chantler has been asked to carry out a rapid review of the evidence that plain packaging could discourage young smokers. This will focus on the pilot scheme in Australia, which became the first country to legislate for standardised packaging in 2011. The review is expected to be completed by March 2014.

BY KATE QUINLAN

\section{RESULTS OF DENTAL CONTRACT STUDY TO BE REVEALED}

University of Liverpool researchers are to reveal the emerging findings of a three-year study into factors influencing responses to NHS contracts in general dental practice, at a conference on 11 February 2014.

The research project, funded by the National Institute of Health Research Health Services and Delivery Research (HSctDR) Programme, examined the tensions involved in working within the framework provided by NHS dental contracts, and why getting dental contracting right (and the commissioning of general dental practice) is challenging.

The research team is holding the event in Liverpool to reveal the findings which include a systematic review of healthcare contracting theory, case studies of dental and medical practices, interviews with a range of stakeholders and commissioners, and the results of a questionnaire to general dental practitioners. The speakers will be Professor Rebecca Harris, Elizabeth Lynam and Professor Jimmy Steele.

Last month the British Dental Association (BDA) warned that new contractual arrangements must work for practitioners and patients alike if confidence in the future of NHS dentistry in England is to be maintained, and to 'avoid the pitfalls seen around the changes in 2006, which prompted many dentists to pursue a future away from the NHS and triggered scenes of queues around the block to access dental care'.

Pilots of a new NHS dental contract are underway, with a new contract expected in 2015.

\section{£30 MILLION NOT ENOUGH TO SAVE LIVES}

Increased Government funding to allow for cheaper and more frequent check-ups would cut the current cost barrier associated with dental care and could ultimately save thousands of live, according to the British Dental Health Foundation.

Research conducted on behalf of the Foundation reveals that almost half of the general public believe investing in dentistry could help to reduce cancer rates; a similar number also called for more investment into cancer research.

Around three in four cases of mouth cancer are detected by dentists, further highlighting the importance of calls for greater investment.

Chief Executive of the Foundation, Dr Nigel Carter OBE, welcomed a recent $£ 400$ million Government investment into cancer research, but said that the $£ 30$ million cash injection into dentistry earlier this year doesn’t go far enough.

\section{WHAT BDJ READERS WERE READING IN $2013^{*} \ldots$}

5. Research - A comparative study of bonded and non-bonded amalgam restorations in general dental practice British Dental Journal 2013; 214: E19

4. Research - Radiation protection in dental X-ray surgeries still rooms for improvement British Dental Journal 2013; 214: E16

3. Practice - Contemporary perspective on the use of fluoride products in caries prevention British Dental Journal 2013; 214: 161-167

. Practice - Minimal intervention dentistry: part 7. Minimally invasive operative caries management: rationale and techniques

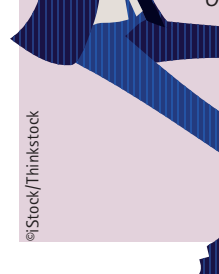

British Dental Journal 2013; 214: 107-111

1. Practice - Caries detection and diagnosis, sealants and management of the possibly carious fissure British Dental Journal 2013; 214: 551-557 